\section{International Scientific Journal Theoretical \& Applied Science}

p-ISSN: 2308-4944 (print) e-ISSN: 2409-0085 (online)

Year: $2017 \quad$ Issue: $06 \quad$ Volume: 50
Ilgar Alakbar Agayev

Candidate of Legal Sciences, Doctoral student of Department of "Economic Security and Management of Social and Economic Processes",

St. Petersburg University of the Ministry of Internal Affairs of Russia, Russian Federation nauka-xxi@mail.ru

Published: $30.06 .2017 \quad$ http://T-Science.org

SECTION 31. Economic research, finance, innovation, risk management.

\title{
THE IMPORTANCE OF STRENGTHENING THE ACTIVITY OF LAW ENFORCEMENT BODIES IN ENSURING AZERBAIJAN'S ECONOMIC SECURITY IN THE FACE OF GROWING GLOBAL THREATS
}

\begin{abstract}
The importance of strengthening the activity of law enforcement bodies in ensuring Azerbaijan's economic security in the face of growing global threats are studied in the article. Important elements and criteria for ensuring the country's economic security, taking into account internal and external factors, features of the national economy, and the level of economic crime are analyzed. The importance and role of law enforcement bodies in ensuring economic security of the country's economy is considered. The actual and modern aspects of the elements of strengthening economic security are studied through the implementation of preventive measures, the organization of preventive works with state and private structures on the issues of transparency of the national economy, accounting and reporting in business entities and commercial organizations. The level of criminality in the economic spheres of Azerbaijan and appropriate conclusions are drawn on reducing the number of economic crimes is considered. The necessity of strengthening the material and technical base of the subdivisions of the internal affairs bodies to counteract economic crimes in the Azerbaijan Republic under the current conditions is
\end{abstract} substantiated.

A number of recommendations and proposals on the importance of strengthening the activities of law enforcement bodies in ensuring Azerbaijan's economic security in the face of growing global threats are given at the end of the article.

Key words: Azerbaijan, economic security, law enforcement agencies, property protection, economic crimes, material and technical base of internal affairs bodies, global threats.

Language: Russian

Citation: Agayev IA (2017) THE IMPORTANCE OF STRENGTHENING THE ACTIVITY OF LAW ENFORCEMENT BODIES IN ENSURING AZERBAIJAN'S ECONOMIC SECURITY IN THE FACE OF GROWING GLOBAL THREATS. ISJ Theoretical \& Applied Science, 06 (50): 139-144.

Soi: http://s-o-i.org/1.1/TAS-06-50-19 Doi: crossef https://dx.doi.org/10.15863/TAS.2017.06.50.19

\section{ВАЖНОСТЬ УСИЛЕНИЯ ДЕЯТЕЛЬНОСТИ ОРГАНОВ ВНУТРЕННИХ ДЕЛ В ОБЕСПЕЧЕНИИ ЭКОНОМИЧЕСКОЙ БЕЗОПАСНОСТИ АЗЕРБАЙДЖАНА В УСЛОВИЯХ РОСТА ГЛОБАЛЬНЫХ УГРОЗ}

Аннотация: В статье исследована важность усиления деятельности органов внутренних дел 6 обеспечении экономической безопасности Азербайджана в условиях роста глобальньх угроз. Анализированы важные элементы и критерии обеспечения экономической безопасности страны с учётом внутренних и внешних факторов, особенностей национальной экономики, уровня экономической преступности. Рассмотрены важность и роль органов внутренних дел по обеспечению экономической безопасности экономики страны. Изучены актуальные и современные аспекты элементов усиления экономической безопасности путём проведения превентивных мер, организации профилактических работ с государственными и частными структурами по вопросам прозрачности национальной экономики, ведения учёта и отчётности в предпринимательских субъектах и коммерческих организациях. Рассмотрен уровень преступности в экономических сферах Азербайджана и сделаны соответствующие выводы по уменьшению числа экономических преступлений. Обоснована необходимость усиления материально-технической базы

ISPC Technology and Education,

Philadelphia, USA 
подразделений органов внутренних дел по противодействию экономическим преступлениям 6 Азербайджанской Республике в нынешних условиях.

В конце статьи дан ряд рекомендаций и предложений по важности усиления деятельности органов внутренних дел в обеспечении экономической безопасности Азербайджана в условиях роста глобальных угроз.

Ключевые слова: Азербайджан, экономическая безопасность, органы внутренних дел, защчита собственности, экономические преступления, материально-техническая база органов внутренних дел, глобальные угрозы.

\section{Introduction}

В современных условиях экономическая безопасность рассматривается исходя из статического подхода, при этом статичность не предполагает рассмотрение объекта в застывшем состоянии. Данной системе характерно движение, при котором система воспроизводится в своем неизменном виде. Эти процессы наблюдаются и в некоторых постсоветских странах, в том числе, в Азербайджане, где углубляются социальноэкономические реформы, которые являются составляющей частью комплексных мер по обеспечению экономической безопасности страны. Дело в том, что в этих условиях воспроизводственная модель экономики развивается по аналогу наименее развитых стран и эти факторы выступают в качестве значимого показателя в оценке системы экономической безопасности. В условиях решения обеспечения динамичного и устойчивого развития национальной экономики, повышения еe конкурентоспособности, существующая модель развития может препятствовать ускоренному вхождению страны в число развитых стран и интеграцию ее в мирохозяйственную систему. Другими словами, страна с такой экономической моделью и тенденциями будет сопровождена так называемой моделью «догоняющей» экономики.

\section{Materials and Methods}

Исследователь Е.Кузнецова выделил важность повышения конкурентоспособности национальной экономики в международной конкурентной борьбе. В современных условиях конкурентоспособность страны может быть надежно обеспечена конкурентными преимуществами. При этом в современных условиях главную роль играют не только наличие в распоряжении страны достаточных природных ресурсов, но и в гораздо большей степени конкурентоспособность зависит от способности всей совокупности производственного потенциала страны. Однако и это является недостаточным условием в достижении экономической безопасности страны[1]. Соглашаясь с автором, можно отметить сырьевую направленность экономики Азербайджана в современных условиях и принятие комплексных мер по развитию ненефтяных секторов экономики страны, в том числе, с учетом развития регионов, отделенных территориальных структур и прочих. Очевидна зависимость темпов роста экономики Азербайджана от нефтегазовых ресурсов и их реализация на экспорт требуют расширения диверсификации национальной экономики страны, совершенствование эффективности деятельности правительственных исполнительных, правоохранительных органов и усиления их роли в процессах обеспечения экономической безопасности в контексте национальной безопасности. Стоит отметить мнение ряда авторов, которые склоняются к определению сущности экономической безопасности как состоянию экономики и государства, где обеспечивается стабильность общественной безопасности и охраны национальных ценностей, в целом защита национальных интересов. При наличии мощного ресурсного потенциала во всех сферах, в том числе внутри и вне экономики страны, обеспечивается интересы народа и в целом, страны[2]. В данном механизме сконцентрированы элементы, которые дадут возможность формированию более эффективной системы безопасности государства. Кроме того, подобные системы экономической безопасности страны требуют более чёткие аргументированные факторы и подходы по прочности системы безопасности в условиях глобальных угроз как внутри страны так извне. Дело в том что, в условиях углубления рыночной экономики требуются те механизмы действия, которые способствуют устойчивому развитию национальной экономики и комплексному решению в социально-экономических проблемах общества. Поэтому, для устойчивости системы экономической безопасности страны необходимо разработать и осуществить действенные меры по пресечению и минимизации экономических угроз. Изучая проблемы методической основы мониторинга факторов, определяющих возникновение угроз экономической безопасности, исследователь А.Мику отмечает, что для обеспечения экономической безопасности как важнейшего элемента национальной безопасности необходима систематическая работа 


\begin{tabular}{|c|c|c|c|c|c|c|}
\hline Impact Factor: & $\begin{array}{l}\text { ISRA (India) } \\
\text { ISI (Dubai, UAF } \\
\text { GIF (Australia) } \\
\text { JIF }\end{array}$ & $\begin{array}{l}=1.344 \\
=0.829 \\
=0.564 \\
=1.500\end{array}$ & $\begin{array}{l}\text { SIS (USA) } \\
\text { PИНЦ (Russia) } \\
\text { ESJI (KZ) } \\
\text { SJIF (Morocco }\end{array}$ & $\begin{array}{l}=0.912 \\
=0.234 \\
=\mathbf{3 . 8 6 0} \\
=\mathbf{2 . 0 3 1}\end{array}$ & $\begin{array}{l}\text { ICV (Poland) } \\
\text { PIF (India) } \\
\text { IBI (India) }\end{array}$ & $\begin{array}{l}=6.630 \\
=1.940 \\
=4.260\end{array}$ \\
\hline
\end{tabular}

по выявлению и предупреждению угроз, по нейтрализации последствий уже возникших неблагоприятных ситуаций[3]. Другой исследователь М.Квитчук, изучая проблемы методов мониторинга масштабов теневой экономики как угрозы экономической безопасности государства, указывает, что структура теневой экономики как источника угроз формируется двумя сегментами производительным и непроизводительным. Основу первого сегмента составляет предпринимательская деятельность, которая может осуществляться в производственной, коммерческой, финансовой и других подсистемах экономической системы государства. Второй сегмент состоит из двух компонентов: социодеструктивного и государственнодеструктивного. В результате социодеструктивной деятельности разрушается человеческий капитал, что подрывает сами основы экономического роста. Следствием государственно-деструктивной деятельности становится, возрастание транзакционных издержек, неэффективное распределение прав собственности[4]. В.Шкварок, исследуя теоретические основы и классификацию угроз экономической безопасности страны, выделил следующие сферы: энергетическая, демографическая, социально-культурная, информационная, военная, промышленная, научно-техническая, политическая, продовольственная, финансовая сферы теневой экономики, глобализация и прочие[5]. Несмотря на приведенную автором группу мер по противодействию угрозам экономической преступности, элементов и почвы, способствующей разного характера угрозам, но даже наиболее оптимальная система превентивных мер не сможет предвидеть, а тем более ликвидировать спонтанно возникающие нестандартные угрозы, способные причинить существенный ущерб экономике страны.

Отметим, что при формировании оптимального распределения полномочий и функциональных задач государственных органов, в том числе правоохранительных органов, по обеспечению экономической безопасности страны, необходимо учитывать ряд факторов и специфических особенностей:

$\square \quad$ информационное обеспечение национальной экономики должно реально характеризовать положение в экономике;

$\square$ экономическая безопасность должна быть реализована на базе разработки проектов социально-экономического развития и государственного бюджета; $\square$ цели и задачи государственных структур, в том числе, правоохранительных органов в вопросах экономической безопасности необходимо четко конкретизировать;

$\square \quad$ сформировать ряд предприятий, продукция которых необходима для обеспечения государственных потребностей;

$\square \quad$ определить ряд конкретных предприятий и осуществить государственную поддержку для повышения их конкурентоспособности;

$\square$ выделить экономические субъекты, в которых контрольный пакет акций закрепляются за государством для воздействия на решения, принимаемые этими субъектами;

$\square$ государству необходимо осуществлять контроль над стабильным функционированием предприятий жизненно важной деятельности населения и базовой сети инфраструктуры и т.д.

Стоит отметить, что в обеспечении экономической безопасности Азербайджана значительная роль отводится правоохранительным органам и, преимущественно, подразделениям МВД. Задачи, реализуемые органами внутренних дел и осуществляемые ими функции, определяют организационную структуру органов внутренних дел, которая состоит из отраслевых и функциональных служб. Отметим, что работа органов МВД серьезно влияет на реализацию экономической безопасности государства. Например, при охране собственности и в процессе реализации концепции экономической безопасности:

$\square$ обеспечение общественного порядка, который считается важным элементом организации экономической безопасности страны;

$\square$ формирование условий для организации труда и отдыха граждан;

$\square$ создание обстановки безопасности и спокойствия в общественных местах;

$\square$ обеспечение непрерывной деятельности организаций и учреждений;

$\square$ усиление борьбы с беспорядками, терроризмом и противодействие кибербезопасности;

$\square$ формирование необходимой среды по улучшению климата в области экономической безопасности государства;

$\square$ раскрытие преступлений и пресечение причинения материального ущерба государству и пр.

Как известно, в составе органов внутренних дел имеется ряд подразделений, которые занимаются выполнением круга задач по 
укреплению экономической безопасности страны. В данной работе из числа отличавшихся организаций можно отметить деятельность Государственной Дорожной Полиции и Налоговую Полицию при Министерстве Налогов Азербайджанской Республики[6]. Эти службы в своей деятельности проводят определённые работы профилактического и аналитического характера экономических преступлений. Кроме того, по мере наличности преступных элементов они проводят соответствующие оперативные меры по пресечению преступных действий, или же задержания нарушителей законности. Имея ряд полномочий по предупреждению, пресечению, выявлению и раскрытию экономических преступлений эти организации способствуют защите граждан страны, которые являются основными потребителями и участниками экономических процессов, где совершается преимущественная часть экономических преступлений[7; 8; 9]. Более того, с развитием предпринимательской деятельности и бизнес-структур в стане требуется расширение географии правовых-организационных мер по пресечению экономических преступлений, права и обязанности сотрудников структур обеспечивающие экономическую безопасность страны в нынешних условиях. Исходя из характера и особенности, работники правоохранительных органов нуждаются в осмотре того или иного помещения, территории и пр. Более того, им необходимо соответствующие полномочия и они нуждаются в обладании права для проведения следственных мероприятий и розыскных работ в разных промышленных и торговых структурах, конкретно требуемых объектах, административных помещениях и ангарных постройках. Подобная необходимость вызвана рассмотрением и изъятием нужных документов и материальных ценностей, которые требуются для следственного разбирательства, проведения специальных денежных и финансовых операций, уточнения наличности остатка товара и ценностей в складских помещениях, чёткого и достоверного учёта продукции, товаров, инвентаря, материальных ценностей, денежных ресурсов и других активов проверяемого субъекта. Каждое из этих действий правоохранительных органов должно сопровождаться определёнными инструкциями, нормативами и законодательными актами, которые добавят уверенности в действия, и в целом, обеспечат эффективность деятельности органам внутренних дел по борьбе с экономическими преступлениями, ликвидации преступных группировок и уменьшению случаев коррупции[10]. Более того, сотрудники органов внутренних дел в ходе работы по выявлению экономических преступлений и коррупционных фактов имеют право получить необходимую информацию и соответствующие объяснения от должностных лиц и ответственных людей за материальные ценности. И при необходимости они имеют право опечатывать и на определённый период закрывать деятельность складских помещений, где хранится продукция, служебные комнаты, и прочие служебные административные помещения, в которых находятся документы, компьютерная техника, денежные кассы, специальные склады и ангары. То есть, работники органов внутренних дел в процессах выполнения должностных обязанностей и поставленных задач по обеспечению экономической безопасности государства должны иметь достаточные полномочия и права по эффективному выполнению своей работы. Только в этом случае увеличатся реальные возможности повышения рациональности общей деятельности органов внутренних дел по борьбе с экономическими нарушениями и преступлениями, минимизации фактов коррупции и деятельности преступных группировок. Кроме того, подразделения органов внутренних дел должны иметь достаточные материальные средства и ресурсы, элементы материально-технической базы для плодотворной деятельности противодействия экономическим преступлениям. Отметим, что в Азербайджане уделяется пристальное внимание на эти проблемы и примерный проект распределения расходов на развитие, сохранение и укрепление материальнотехнической базы органов внутренних дел Азербайджанской Республики в рамках проекта Государственной Программы «О совершенствовании деятельности органов полиции в Азербайджанской Республике в 2016-2020 гг.» отражен на Рисунке 1.

В современных условиях необходимо увеличить средства, выделенные на развитие материально-технического обеспечения и обеспечения информационными технологиями, которые позволят увеличить эффективность мероприятий по укреплению экономической безопасности Азербайджанской Республики в современных условиях. 


\begin{tabular}{|c|c|c|c|c|c|c|}
\hline Impact Factor: & $\begin{array}{l}\text { ISRA (India) } \\
\text { ISI (Dubai, UAF } \\
\text { GIF (Australia) } \\
\text { JIF }\end{array}$ & $\begin{array}{l}=1.344 \\
=0.829 \\
=0.564 \\
=1.500\end{array}$ & $\begin{array}{l}\text { SIS (USA) } \\
\text { PИНЦ (Russia) } \\
\text { ESJI (KZ) } \\
\text { SJIF (Morocco }\end{array}$ & $\begin{array}{l}=0.912 \\
=\mathbf{0 . 2 3 4} \\
=\mathbf{3 . 8 6 0} \\
=\mathbf{2 . 0 3 1}\end{array}$ & $\begin{array}{l}\text { ICV (Poland) } \\
\text { PIF (India) } \\
\text { IBI (India) }\end{array}$ & $\begin{array}{l}=6.630 \\
=1.940 \\
=4.260\end{array}$ \\
\hline
\end{tabular}

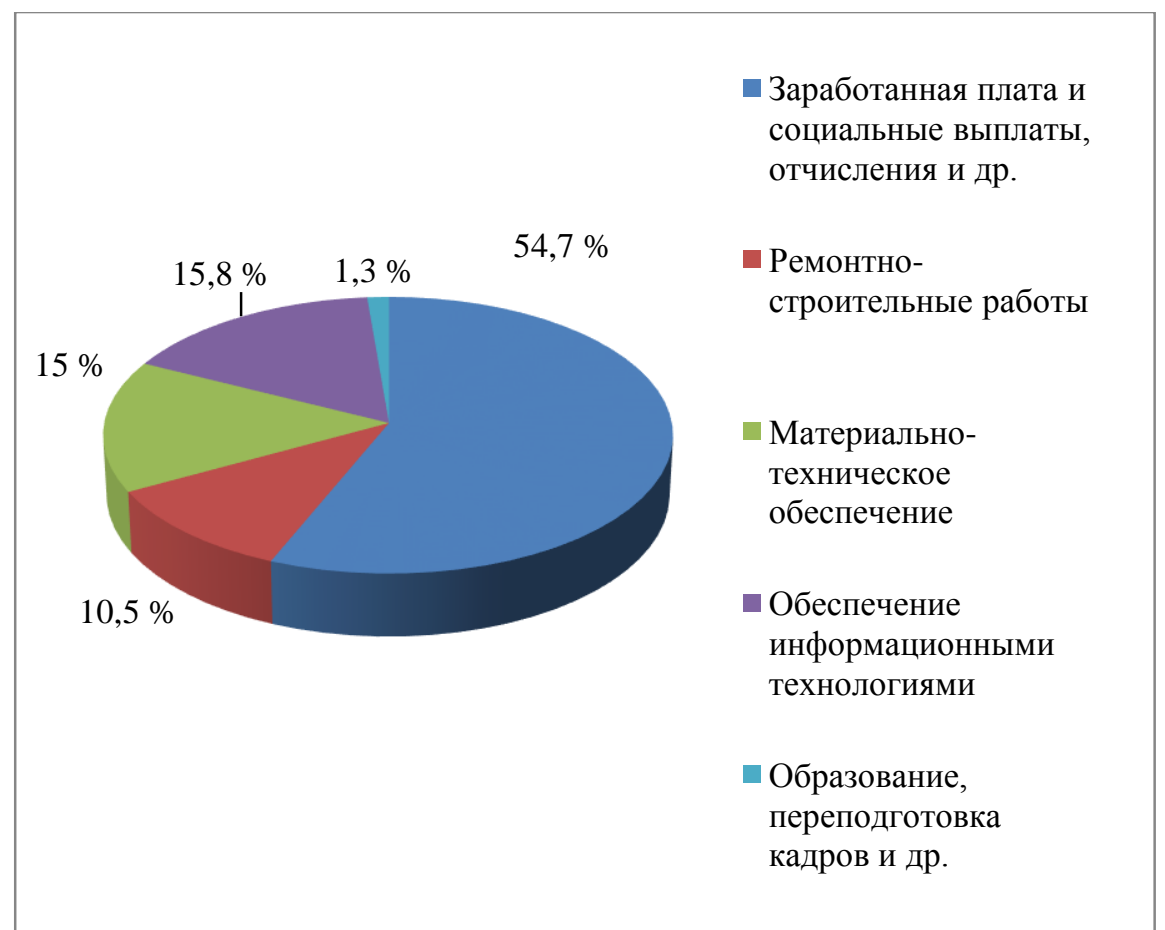

Рисунок 1 - Распределение расходов на развитие, сохранение и укрепление материально-технической базы органов внутренних дел Азербайджанской Республики в рамках проекта Государственной Программы «О совершенствовании деятельности органов полиции в Азербайджанской Республике в 20162020 гг.», в \% (разработано автором).

\section{Conclusion}

Таким образом, исходя из совокупности деятельности органов внутренних дел по обеспечению экономической безопасности страны с целью поднятия эффективности их реализации, можно отметить следующие проблемы:

$\square$ несовершенство существующего законодательства и нормативных актов;

$\square \quad$ недостаточное применение передового мирового опыта и эффективных механизмов предупреждения преступлений и противоправной деятельности в экономических сферах;

$\square$ слабые профессиональные навыки сотрудников органов внутренних дел и их неэффективная работа в обстановке хаотично формирующихся договорных отношений, полной независимости экономических субъектов и свободы субъектов бизнеса;

отсутствие оперативности и четкой стратегии в организации и реализации ревизий финансовой деятельности и проверок документов предприятий экономических субъектов;

низкий уровень социальной

незащищенности работников органов внутренних дел, необходимость принятия дополнительных мероприятий по укреплению материально-технической базы органов внутренних дел по противодействию экономическим преступлениям и т.д. 


\begin{tabular}{l|lrl|l|ll} 
& ISRA (India) & $=\mathbf{1 . 3 4 4}$ & SIS (USA) & $=\mathbf{0 . 9 1 2}$ & ICV (Poland) & $=\mathbf{6 . 6 3 0}$ \\
Impact Factor: & ISI (Dubai, UAE) $=\mathbf{0 . 8 2 9}$ & PUHU (Russia) $=\mathbf{0 . 2 3 4}$ & PIF (India) & $=\mathbf{1 . 9 4 0}$ \\
& GIF (Australia) & $\mathbf{0 . 5 6 4}$ & ESJI (KZ) & $=\mathbf{3 . 8 6 0}$ & IBI (India) & $\mathbf{4 . 2 6 0}$
\end{tabular}

\section{References:}

1. Kuznetsova YI (2010) Metodologiya formirovaniya ekonomicheskoy strategii gosudarstva: ekonomicheskaya bezopasnost' i konkurentosposobnost'. Diss. d-ra ekon. nauk, Moskva, 2010.-350 p.

2. Senchagov VK (2007) Byudzhetnaya politika i yeye rol' $\mathrm{v}$ obespechenii ekonomicheskogo rosta//Voprosy ekonomiki. 2007. № 5.-p. 32-44.

3. Miku AA (2009) Metodicheskiye osnovy monitoringa faktorov, opredelyayushchikh vozniknoveniye ugroz ekonomicheskoy bezopasnosti Rossiyskoy Federatsii. Diss. kand. ekon. nauk, Sankt-Peterburg, 2009.-164 p.

4. Kvitchuk MA (2009) Metody monitoringa masshtabov tenevoy ekonomiki kak ugrozy ekonomicheskoy bezopasnosti gosudarstva. Diss. kand. ekon. nauk, Sankt-Peterburg, 2009.$125 \mathrm{p}$.

5. Shkvarok VM (2009) Teoreticheskiye osnovy i klassifikatsiya ugroz ekonomicheskoy bezopasnosti strany. Diss. kand. ekon. nauk, Sankt-Peterburg, 2009.-185 p.
6. (2017) Ministerstvo Nalogov Azerbaydzhanskoy Respubliki http://www.taxes.gov.az.

7. Skvortsova VA, Fomina AS (2012) Teoretikometodologicheskikh osnov issledovaniya ekonomicheskoy sostavlyayushchey $\mathrm{v}$ sisteme natsional'noy bezopasnosti otmechayut prioritetnost' ekonomicheskoy bezopasnosti // Izvestiya PGPU im. V.G. Belinskogo. 2012. № 28. - p. 562-565.

8. Slizkaya VP (2009) Ekonomicheskaya bezopasnost' kommercheskoy organizatsii i rol' organov vnutrennikh del v yeye obespechenii. Diss. kand. ekon. nauk. Sankt-Peterburg, 2009. $-214 \mathrm{p}$.

9. Tarasov YA (2013) Rol' i mesto MVD Rossii kak sub"yekta i ob"yekta gosudarstvennogo kontrolya $\mathrm{V}$ sisteme preduprezhdeniya prestupleniy// Rossiyskiy issledovatel', № 20, 2013.

10. Shugurova VP (2013) Zarubezhnyy opyt organizatsii gosudarstvennogo finansovogo kontrolya / V. P. Shugurova, M. F. Zheltova // Molodoy uchenyy. 2013, №1.- p. 209-212. 